\title{
New proposed fractional-polynomial functions: new recommendation for overcome the imbalance in three-phase systems
}

\author{
Q. S. Vu', Bui Vu Minh², Minh Tran³ ${ }^{3}$ N.V. Korovkin ${ }^{4}$ \\ ${ }^{1}$ Faculty of Automobile Technology, Van Lang University, Ho Chi Minh City, Vietnam \\ ${ }^{2}$ Faculty of Mechanical, Electrical, Electronic \& Automotive Engineering, Nguyen Tat Thanh University, Ho Chi Minh \\ City, Vietnam \\ ${ }^{3}$ Optoelectronics Research Group, Faculty of Electrical and Electronics Engineering, Ton Duc Thang University, Ho Chi \\ Minh City, Vietnam \\ ${ }^{4}$ Peter the Great St. Petersburg State Polytechnic University, Saint Petersburg, 195251, Russia
}

\begin{tabular}{|c|c|}
\hline Article Info & ABSTRACT \\
\hline Article history: & Non-linear loads or load imbalances, etc., are the typical causes of asymmetric \\
\hline Received Oct 29, 2020 & $\begin{array}{l}\text { three-phase systems. The appearance of inverse (positive) and } \\
\text { zero) symmetric components cause damage to the systems and }\end{array}$ \\
\hline Revised Sep 30, 2021 & electrical equipment and increase the power losses on the transmission lines. \\
\hline Accepted Oct 5, 2021 & $\begin{array}{l}\text { Reactive power compensation is one of the solutions that can overcome this } \\
\text { asymmetry. The difficulty that exists in many different methods is the optimal }\end{array}$ \\
\hline Keywords: & $\begin{array}{l}\text { calculation of the value of the compensator. In this paper, a new method to } \\
\text { overcome these problems is proposed and investigagted. The proposed method }\end{array}$ \\
\hline $\begin{array}{l}\text { Asymmetric } \\
\text { Fractional-polynomial function } \\
\text { Optimization }\end{array}$ & $\begin{array}{l}\text { is based on the fundamental electrical quantities (voltages and currents) on the } \\
\text { controllable values of the static compensation devices and overcoming of the } \\
\text { asymmetric operation regime in the three-phase systems. }\end{array}$ \\
\hline
\end{tabular}

This is an open access article under the $\underline{C C B Y-S A}$ license.

Regulable parameter

Steady state mode

Three-phase systems

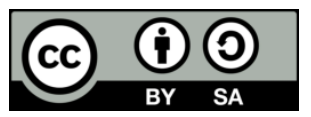

\section{Corresponding Author:}

Minh Tran

Optoelectronics Research Group, Faculty of Electrical and Electronics Engineering

Ton Duc Thang University

Ho Chi Minh City, Vietnam

Email: tranhoangquangminh@tdtu.edu.vn

\section{INTRODUCTION}

The three-phase power distribution system is one of the most popular in the world, and it allows to transfer of energy from production to consumption much more efficiently than single-phase power transmission systems. One of the problems of three-phase systems is that the power consumption is not evenly distributed between the phases, as a result of which the system becomes unbalanced, causing an increase in energy losses and damage to electrical equipment. The imbalance in the three-phase systems is one of the most critical issues of the three-phase system, it has been extensively studied for many years, and specific achievements have been achieved in solving this problem [1]-[5]. Thanks to computerization, it has become possible to apply highly sophisticated and automated methods to improve the quality of the systems. The negative sequence currents create a magnetic field that rotates (against the direction of rotation of the synchronous machine), which retards the rotor. These fields also induce currents of doubled frequency in the rotor of machines with a cylindrical rotor at the poles of the salient-pole machines. These currents induced overheat the rotor. Heating, in turn, leads to a loss of mechanical integrity or failure of the electrical 
machine's insulation. In asynchronous motors, even a $5 \%$ imbalance can result in a $25 \%$ reduction in engine power. The imbalance presents in the supply voltage by $3 \%$ can increase the heating of the rotor by about $20 \%$, so three-phase machines must be protected against unbalanced currents [6].

For some applications, it is possible to reduce the imbalance by changing the operating parameters. To reduce the effect of negative sequence currents, a cause of the negative sequence voltage drops, the supply voltage requires a low impedance of the internal system. However, applying this method in rural networks is complicated because it is rather challenging to select a single-phase, automatically switched the load of the appropriate power. Therefore, it is not possible to significantly reduce the load asymmetry. In addition, when using balanced devices of this type, the reliability of the power supply of single-phase switchable load decreases; The measuring and commutation complex of these devices seems rather complicated. Another mitigation method is the use of special transformers such as a three-phase or threephase transformer or Scott and Steinmetz transformers [7]-[10]. Transformer balanced three-phase can reduce energy losses by reducing the amplitudes of harmonics, reducing the resistance. This increases the working life of energy sources in networks with phase misalignments. The devices are designed to increase the reliability of autonomous generators and consumers when the loads are asymmetrical and for balancing phase voltages by decreasing the resistance of the zero sequence, so that the same phase bias in the voltage is eliminated, which happens mainly due to the asymmetry of the load currents phases. Reactive power compensation can be performed using a synchronous generator to generate or collect reactive power, but it has that disadvantage: the high cost of installation, maintenance, and complex operation. Synchronous generators are often used to concentrate compensation with a large capacitance, and a compensation capacitor overcomes the disadvantages of a synchronous generator, but the drawback is only for use with the system's bandwidth small, sensitive to voltage changes.

Combined balancing devices always give the best result; however, they are becoming more complex in the calculation, and the number of compensating components necessary for total compensation requires more. The cost of the compensation system also increases. Considering the growing demand for power systems for measures to improve energy quality and reduce the cost of investments and maintenance costs of power quality improvement systems, we need proposals that ensure low-cost symmetrization of three-phase systems [10]-[15]. The complexity of consumption patterns causes difficulty and even impossibility to create a general method for optimizing the unbalanced system. The design of universal symmetrizing systems requires a combination of several approaches and several devices. This leads to an increase in the cost of creation and maintenance. For example, in many cases, for industrial load, the repeatability of load characteristics (including their asymmetry) is observed at different time scales from daily to annual. This circumstance makes it possible to simplify and reduce the cost of symmetrization systems, which is essential since investment costs are the user's primary concern within the acceptable quality of electric systems. With these analyses, we describe the methodology for optimizing three-phase systems operating in asymmetric modes. In meeting the requirements for the quality of the three-phase power system and the investment costs, this approach aims to reduce the number of reactive power compensation devices [15]-[20].

\section{RESEARCH METHOD}

\subsection{New proposed fractional-polynomial functions}

Assume that we have a three-phase circuit consisting of $(n+1)$ nodes and $m(n+1<m)$ branch and described by the matrix of link nodes [10-20]:

$$
\mathbf{A}=\begin{array}{lll}
a_{11} & a_{12} & a_{1 m} \\
a_{21} & a_{22} & a_{2 m} \\
a_{n 1} & a_{n 2} & a_{n m}
\end{array}
$$

Vector of the conductance of the branches is

$$
\mathbf{Y}=\operatorname{diag}\left(Y_{1}, Y_{2}, \ldots Y_{m}\right)
$$

Vectors of current and electromotive force sources is formulated as

$$
\begin{aligned}
& \mathbf{J}=\left(J_{1}, J_{2}, \ldots J_{m}\right)^{t} \\
& \mathbf{E}=\left(E_{1}, E_{2}, \ldots E_{m}\right)^{t}
\end{aligned}
$$

The node voltage equations are written in matrix form as: [18] 


$$
\mathrm{AYA}^{t} \mathrm{U}_{0}=-\mathrm{A}(\mathrm{J}+\mathrm{YE})
$$

The node voltages can be found by the Cramer formula [19]-[21]:

$$
U_{i}=\frac{\operatorname{det} \mathbb{Y}_{i}}{\operatorname{det} \mathbb{Y}}
$$

The matrix $\mathbb{Y}$ will be:

$$
\mathbb{Y}=\begin{array}{ccccc}
1 & \mathbb{Y}_{1,1} & \mathbb{Y}_{1, i} & \mathbb{Y}_{1, j} & \mathbb{Y}_{1, n} \\
\mathrm{i} & \mathbb{Y}_{i, 1} & \mathbb{Y}_{i, i} & \mathbb{Y}_{i, j} & \mathbb{Y}_{i, n} \\
\mathrm{j} & \mathbb{Y}_{j, 1} & \mathbb{Y}_{j, i} & \mathbb{Y}_{j, j} & \mathbb{Y}_{j, n} \\
\mathrm{n} & \mathbb{Y}_{n, 1} & \mathbb{Y}_{n, i} & \mathbb{Y}_{n, j} & \mathbb{Y}_{n, n}
\end{array}
$$

The matrix determinants of $\mathbb{Y}$ and $\mathbb{Y}_{i}$ are defined as follows: (here and were with sign (*), are results of the circuit analysis we have done on the maple software, and due to the limitations of paper we will not present in more detail).

$$
\begin{aligned}
& \operatorname{det} \mathbb{Y}=a_{0}+a_{1} x_{1}+a_{2} x_{2}+a_{3} x_{1} x_{2}=a_{0}\left(1+\frac{a_{1}}{a_{0}} x_{1}+\frac{a_{2}}{a_{0}} x_{2}+\frac{a_{3}}{a_{0}} x_{1} x_{2}\right) \\
& \operatorname{det} \mathbb{Y}_{i}=b_{0, i}+b_{1, i} x_{1}+b_{2, i} x_{2}+b_{3, i} x_{1} x_{2}
\end{aligned}
$$

In general, voltages will be:

$$
\begin{aligned}
& U_{i}=\frac{\operatorname{det} \mathbb{Y}_{i}}{\operatorname{det} \mathbb{Y}}=\frac{b_{0, i}+b_{1, i} x_{1}+b_{2, i} x_{2}+b_{3, i} x_{1} x_{2}}{a_{0}\left(1+\frac{a_{1}}{a_{0}} x_{1}+\frac{a_{2}}{a_{0}} x_{2}+\frac{a_{3}}{a_{0}} x_{1} x_{2}\right)} \\
& \text { Let } \alpha_{p}=a_{p} / a_{0} ; p=1 \div 3 \text { and } c_{q, i}=b_{q, i} / a_{0} ; ; q=0 \div 3 \text {, we have: } \\
& U_{i}=\frac{\operatorname{det} \mathbb{Y}_{i}}{\operatorname{det} \mathbb{Y}}=\frac{c_{0, i}+c_{1, i} x_{1}+c_{2, i} x_{2}+c_{3, i} x_{1} x_{2}}{1+\alpha_{1} x_{1}+\alpha_{2} x_{2}+\alpha_{3} x_{1} x_{2}}
\end{aligned}
$$

If the $i$-th branch connects two nodes $j$-th and $k$-th, the current flow in that from $k$ to $j$, in general, as:

$$
I_{i}=\frac{d_{0, i}+d_{1, i} x_{1}+d_{2, i} x_{2}+d_{3, i} x_{1} x_{2}}{1+\alpha_{1} x_{1}+\alpha_{2} x_{2}+\alpha_{3} x_{1} x_{2}}
$$

Coefficients $\alpha_{1} \ldots \alpha_{3}$ in this case has the same value as the coefficients of the voltages, $i=1 \div m-$ index of branches [20]-[24].

\subsection{Testing}

In the second experiment (proposed functions), we performed as described in section 2. The example circuit is shown in Figure 1. The error between two experiments was calculated by the formula:

$$
\varepsilon\left(x_{1}, x_{2}\right)=100 \%\left|\frac{\left|g_{1}\left(x_{1}, x_{2}\right)\right|-\left|g_{2}\left(x_{1}, x_{2}\right)\right|}{g_{1}\left(x_{1}, x_{2}\right)}\right|
$$

here $g_{m}\left(x_{1}, x_{2}\right)=\left\{\dot{I}_{m, A}^{(j, k)}\left(x_{1}, x_{2}\right)\right.$ or $\left.\dot{U}_{m, A}^{(j, k)}\left(x_{1}, x_{2}\right)\right\} ; j, k=\overline{0,4} ; j \neq k ; m=1,2-$ currents (voltages) of the first experiment and the proposed method [25]-[33].

In Figure 2 and Figure 3, present the errors $\varepsilon_{I}\left(x_{1}, x_{2}\right)$ of current and $\varepsilon_{U}\left(x_{1}, x_{2}\right)$ of the voltage of the proposed FPF without considering random errors $\left(\varepsilon_{r}=0\right)$, such as errors of measurement or constant change of load etc. However, this case does not exist in practice, so we had taken into account random error in the range of $\varepsilon_{r}= \pm 0.5 \%$ and $\pm 1 \%$. The errors were presented as in Figures 4 to 7 . The root means square (RMS) values of the errors were calculated by the formula, and the results will be contained in the Table 1 .

$$
\varepsilon_{R M S}=\sqrt{\frac{1}{p} \frac{1}{q} \sum_{i=1}^{p} \sum_{j=1}^{q} \varepsilon^{2}\left(x_{1}^{(i)}, x_{2}^{(j)}\right)}
$$

here $p, q$ - the lengths of vector $x_{1}, x_{2}$. 
(0)

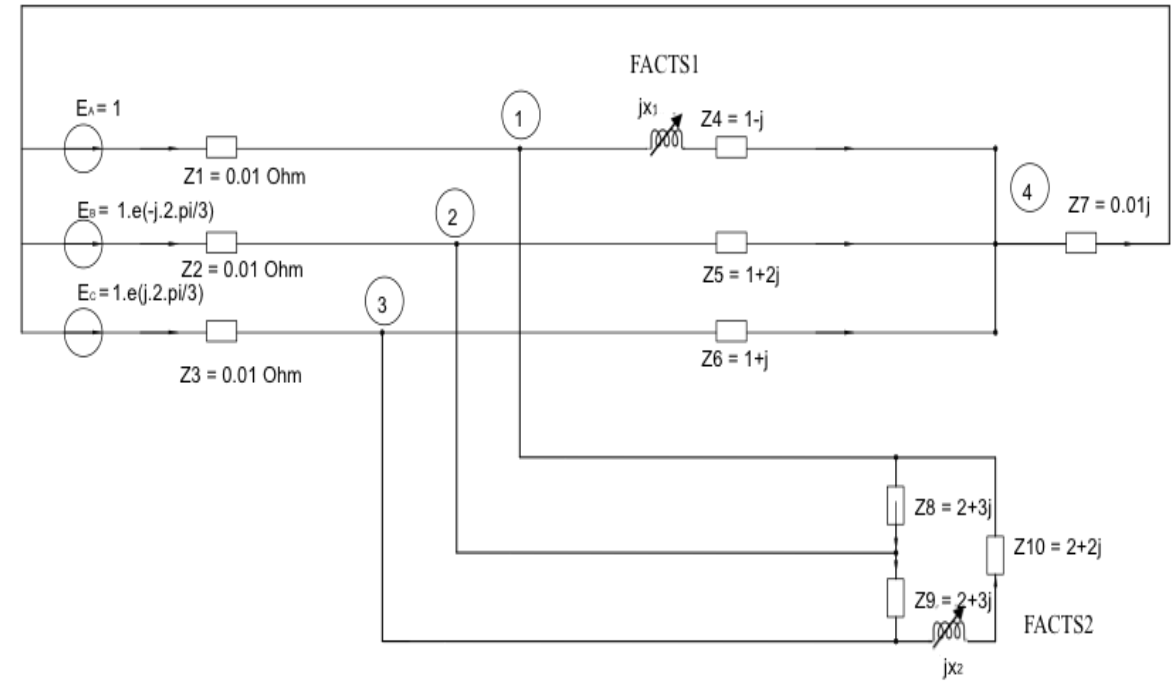

Figure 1. Example circuit

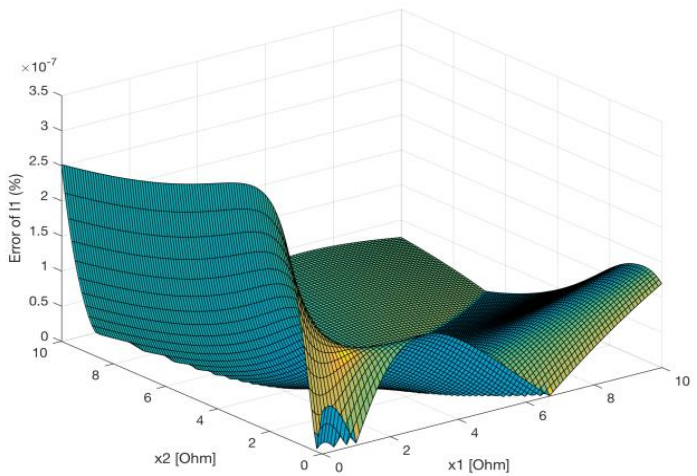

Figure 2. Dependence of error in determining the value of the error $\varepsilon_{I}$ on reactance's values $x_{1}, x_{2}$, when $\varepsilon_{r}=0 \%$

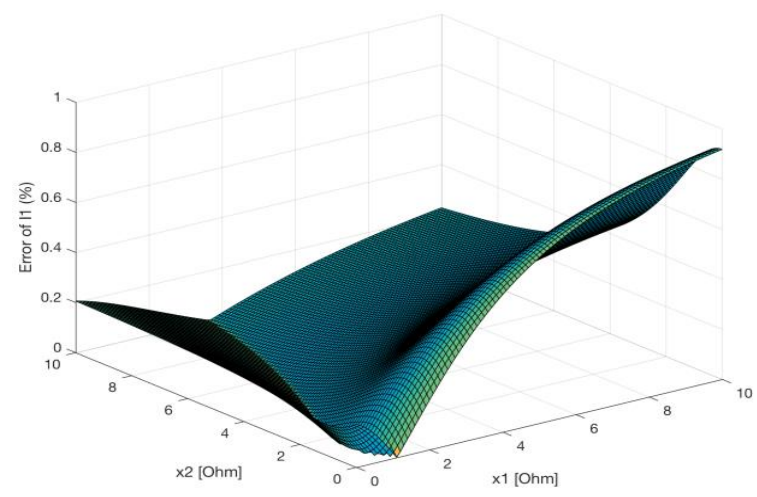

Figure 4. Dependence of error in determining the value of the error $\varepsilon_{I}$ on reactance's values $x_{1}, x_{2}$, when $\varepsilon_{r}=0.5 \%$.

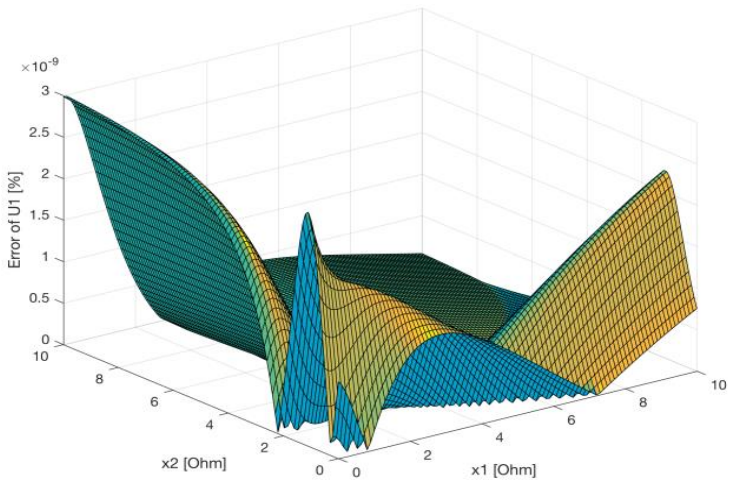

Figure 3. Dependence of error in determining the value of the error $\varepsilon_{U}$ on reactance's values $x_{1}, x_{2}$, when $\varepsilon_{r}=0 \%$

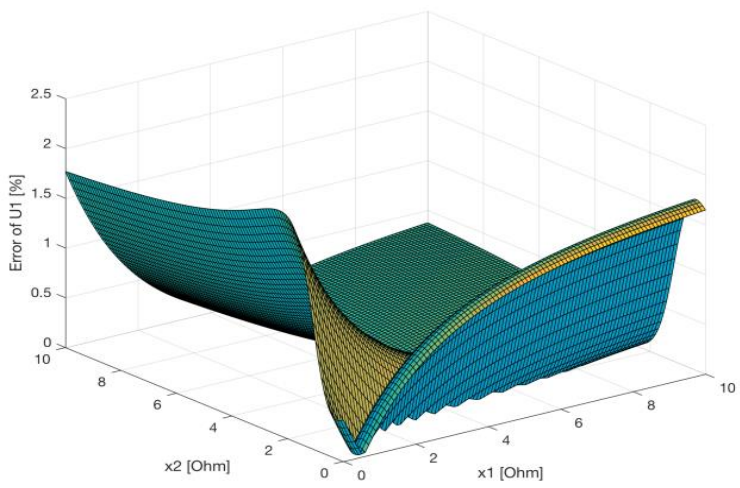

Figure 5. Dependence of error in determining the value of the error $\varepsilon_{U}$ on reactance's values $x_{1}, x_{2}$, when $\varepsilon_{r}=0.5 \%$. 


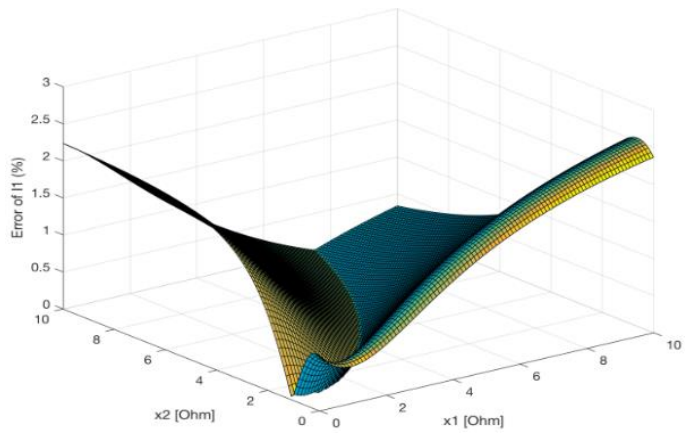

Figure 6. Dependence of error in determining the value of the error $\varepsilon_{I}$ on reactance's values $x_{1}, x_{2}$, when $\varepsilon_{r}=1 \%$

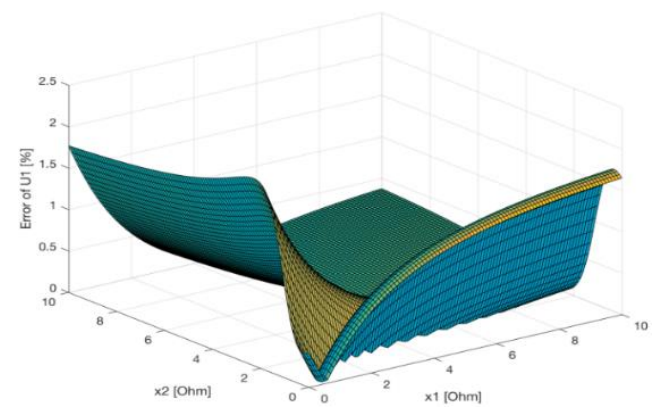

Figure 7. Dependence of error in determining the value of the error $\varepsilon_{U}$ on reactance's values $x_{1}, x_{2}$, when $\varepsilon_{r}=1 \%$

Table 1. The RMS values of the errors depend on $\varepsilon_{r}$

\begin{tabular}{llcl}
\hline & \multicolumn{3}{c}{$\varepsilon_{r}, \%$} \\
\hline & 0 & 0.5 & 1 \\
$\varepsilon_{R M S, I} \%$ & $6.87 \cdot 10^{-8}$ & 0.34 & 1.14 \\
$\varepsilon_{R M S, U}, \%$ & $9.02 \cdot 10^{-10}$ & 0.73 & 7.98 \\
\hline
\end{tabular}

We had repeatedly executed it ( $\mathrm{n}=1000$ times) to assess errors and accurately received average errors.

$$
\bar{\varepsilon}\left(x_{1}, x_{2}\right)=\frac{1}{n} \sum_{i=1}^{n} \bar{\varepsilon}_{i}\left(x_{1}, x_{2}\right)[\%]
$$

The RMS values of the average errors are contained in Table 2.

$$
\bar{\varepsilon}_{R M S}=\sqrt{\frac{1}{p} \frac{1}{q} \sum_{i=1}^{p} \sum_{j=1}^{q} \bar{\varepsilon}^{2}\left(x_{1}^{(i)}, x_{2}^{(j)}\right)}
$$

where $p, q$ - the lengths of vector $x_{1}, x_{2}$.

Table 2. The dependencies of the root mean square errors on $\varepsilon_{r}$

\begin{tabular}{llll}
\hline & \multicolumn{3}{c}{$\varepsilon_{r}, \%$} \\
& 0 & 0.5 & 1 \\
\hline $\bar{\varepsilon}_{R M S, I}, \%$ & $6.87 \cdot 10^{-8}$ & 1.31 & 2.59 \\
$\bar{\varepsilon}_{R M S, U} \%$ & $9.02 \cdot 10^{-10}$ & 1.58 & 3.01 \\
\hline
\end{tabular}

As we can see, the most significant error of the proposed method is under $2 \%$, when the most significant random error of $\varepsilon_{r}=0.5 \%$ and about $3 \%$ when $\varepsilon_{r}=1 \%$. The accuracy of fractional-polynomial functions depends on the error of measurement. Nowadays, the development of measurement devices with high quality makes a tiny error $\varepsilon_{r}<0.5 \%$, however, in this article, we not only take into account the errors of measurement but also including the constant change of load as shown in Figure 8.

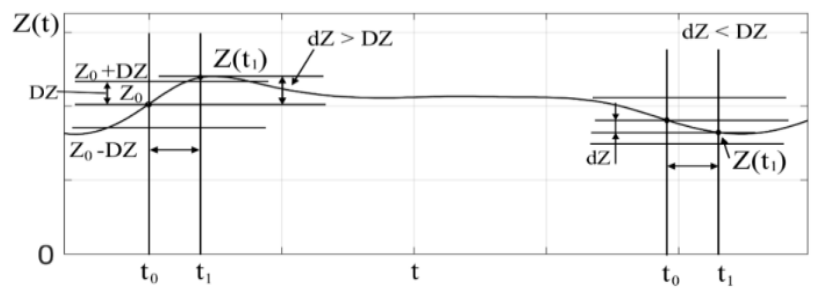

Figure 8. The constant change of loads

Permissible change limits of load: 


$$
\begin{aligned}
& \varepsilon_{r}=\frac{\left|Z\left(t_{0}\right)-Z\left(t_{1}\right)\right|}{Z\left(t_{0}\right)}=\frac{\mathrm{D} Z}{Z_{0}} 100 \% \\
& \mathrm{~d} Z=\left|Z-Z_{0}\right|
\end{aligned}
$$

where $Z_{0}=Z\left(t_{0}\right)$ - impedance at the beginning of the calculation; $Z\left(t_{1}\right)$-impedance at the end of the calculation. At moment $t_{1}$, the calculation process is completed, and the values $\left(x_{1}, x_{2}\right)$ received will be applied to the compensation system if $\mathrm{d} Z<\mathrm{D} Z$.

\section{NUMERICAL RESULTS AND DISCUSSION}

Sequence components are formulated as [20]-[37]:

$\left[\begin{array}{l}\dot{I}_{1}^{(j, k)}\left(x_{1}, x_{2}\right) \\ \dot{I}_{2}^{(j, k)}\left(x_{1}, x_{2}\right) \\ \dot{I}_{0}^{(j, k)}\left(x_{1}, x_{2}\right)\end{array}\right]=\left[\begin{array}{ccc}1 & 1 & 1 \\ a^{2} & a & 1 \\ a & a^{2} & 1\end{array}\right]^{-1} \cdot\left[\begin{array}{l}\dot{I}_{A}^{(j, k)}\left(x_{1}, x_{2}\right) \\ \dot{I}_{B}^{(j, k)}\left(x_{1}, x_{2}\right) \\ \dot{I}_{C}^{(j, k)}\left(x_{1}, x_{2}\right)\end{array}\right]$.

where $j, k=\overline{1, N} ; j \neq k$; We got:

$\dot{I}_{m}^{(j, k)}\left(x_{1}, x_{2}\right)=\frac{a_{i, m}^{(j, k)}+b_{i, m}^{(j, k)} x_{1}+c_{i, m}^{(j, k)} x_{2}+d_{i, m}^{(j, k)} x_{1} x_{2}}{1+\alpha_{1} x_{1}+\alpha_{2} x_{2}+\alpha_{3} x_{1} x_{2}}$.

Negative and zero sequence components appear in asymmetrical systems, and they have greater values when the system is more asymmetric.

$$
\left\{\begin{array} { l } 
{ | \dot { I } _ { 1 } ^ { ( j , k ) } ( x _ { 1 } , x _ { 2 } ) | \rightarrow \operatorname { m a x } } \\
{ | \dot { I } _ { 2 } ^ { ( j , k ) } ( x _ { 1 } , x _ { 2 } ) | \rightarrow \operatorname { m i n } , \text { or } } \\
{ | \dot { I } _ { 0 } ^ { ( j , k ) } ( x _ { 1 } , x _ { 2 } ) | \rightarrow \operatorname { m i n } }
\end{array} \left\{\begin{array}{l}
f_{1}=1 /\left|\dot{I}_{1}^{(j, k)}\left(x_{1}, x_{2}\right)\right| \rightarrow \min \\
f_{2}=\left|\dot{I}_{2}^{(j, k)}\left(x_{1}, x_{2}\right)\right| \rightarrow \min \\
f_{3}=\left|\dot{I}_{0}^{(j, k)}\left(x_{1}, x_{2}\right)\right| \rightarrow \min
\end{array}\right.\right.
$$

Let $F(X)=\left\{f_{1}, f_{2}, f_{3}\right\}$

The multi-objective optimization problem can be brought back to mathematical form and described as follow [2], [12]

$$
\begin{aligned}
& \min F\left(x_{1}, x_{2}\right)=\left\{f_{1}\left(x_{1}, x_{2}\right), f_{2}\left(x_{1}, x_{2}\right), f_{3}\left(x_{1}, x_{2}\right)\right\}^{T} \\
& \text { s.t. }\left(x_{1}, x_{2}\right) \in X,
\end{aligned}
$$

where the integer $k \geq 2$ is the number of objectives, and the set $X$ is the feasible set of decision vectors. The valued vector of the objective function is defined as:

$$
F: X \rightarrow \mathbb{R}^{k}
$$

Therefore, $X \_1$ is a non-dominated solution and $X \_2$ is an inferior solution. The solution $X \_1$ will be called dominated solution if:

$$
\forall i=1 . .3: f_{i}\left(X_{1}\right) \leq f_{i}\left(X_{2}\right)
$$

Typically, in the multi-objective optimization problem, we often encounter non-denominated solutions rather than denominated solutions. As we can see in Figure 9 in 2-D coordinate system. The most important relationship between all objectives is the Pareto front, and we can choose the appropriate solution as the optimal solution of the problem when we gave a weight coefficient to each objective [22]-[27]. For multi-objective optimization problems solved by genetic algorithms. The set of solutions after every single loop of the iteration is called generation. An initial set of solutions is randomly selected and designated as the first generation. In every iteration loop, the genetic operators, selection, crossover, and mutation are applied 
to the previous solutions (previous generation) to generate the new solutions. The final set of solutions, also called Pareto font, was obtained after a certain number of iterations [15].

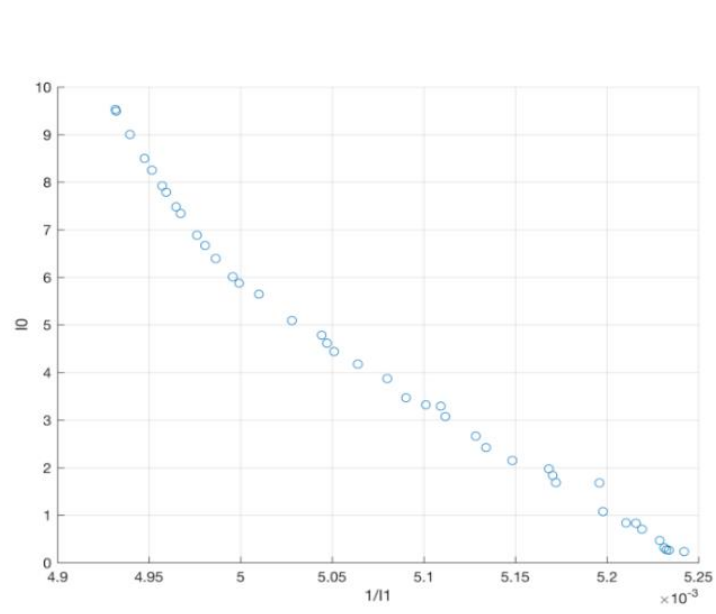

Figure 9. Pareto front in 2-D coordinate system

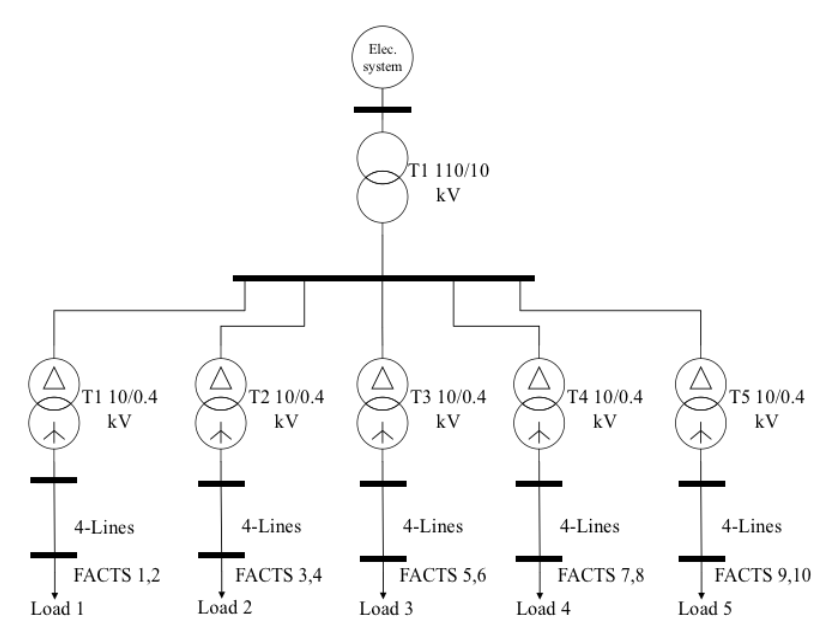

Figure 10. Electrical system of the glass factory

\section{CONCLUSION}

In this paper, a new method to overcome these problems is proposed and investigagted. The proposed method is based on the fundamental electrical quantities (voltages and currents) on the controllable values of the static compensation devices and overcoming of the asymmetric operation regime in the threephase systems. Furthermore, the efficiency and method speed are improved by intelligent search algorithms (NSGA, GA). The research results show that the new mothed is powerful and efficiency.

\section{REFERENCES}

[1] J. J. G. W. D. Stevenson, Power system analysis. New York: McGraw-Hill, 1994.

[2] C. L. Fortescue, "Method of Symmetrical Co-Ordinates Applied to the Solution of Polyphase Networks," Trans. Am. Inst. Electr. Eng., vol. XXXVII, no. 2, pp. 1027-1140, July 1918, doi: 10.1109/T-AIEE.1918.4765570.

[3] L. S. Czarnecki, and P. M. Haley, "Unbalanced Power in Four-Wire Systems and Its Reactive Compensation," IEEE Trans. Power Deliv., vol. 30, no. 1, pp. 53-63, 2015, doi: 10.1109/TPWRD.2014.2314599.

[4] M.V. Sudhkar, and L. K. Sahu, "Simulation of Generator Negative Sequence Protection Using Matlab," Int. J. Eng. Sci. Comput., vol. 7, no. 5, pp. 12487-12494, 2017.

[5] Y. Li, and P. A. Crossley, "Voltage balancing in low-voltage radial feeders using Scott transformers," IET Gener. Transm. Distrib., vol. 8, no. 8, pp. 1489-1498, 2014, doi: 10.1049/iet-gtd.2013.0528.

[6] Y. Aihara, R. Miyazawa, and H. Koizumi, "A study on the effect of the Scott transformer on the three-phase unbalance in distribution network with single-phase generators," 2012 3rd IEEE International Symposium on Power Electronics for Distributed Generation Systems (PEDG), 2012, pp. 283-290, doi: 10.1109/PEDG.2012.6254015.

[7] N.V. Korovkin, L. Neiman, and K. Demirchyan, Theoretical Foundations of Electrical Engineering, SPB: Peter.

[8] N. G. Hingorani, and L. Gyugyi, Understanding FACTS: Concepts and Technology of Flexible AC Transmission Systems, New Jersey: Wiley-IEEE Press, 1999.

[9] Y. H. Song, and A. T. Johns, Flexible AC Transmission Systems, London: IEEE Press, 1999.

[10] M. Young, The Technical Writer's Handbook, California: University Science, 1989.

[11] L. Thévenin, Extension of Ohm's law to complex electromotive circuits. Annales. 3e series. 10: 222-224.

[12] L. Thévenin, On a new theorem of dynamic electricity. Sciences. 97: 159-161.

[13] J. E. Brittain, “Thevenin's theorem," in IEEE Spectrum, vol. 27, no. 3, pp. 42-, March 1990, doi: 10.1109/6.48845.

[14] E. L. Norton, "Design of finite networks for uniform frequency characteristic," Bell Laboratories, New Jersey, U.S, Technical Report TM26-0-1860, 1926.

[15] K. M. Chandy, U. Herzog, and L. Woo, "Parametric Analysis of Queuing Networks," in IBM Journal of Research and Development, vol. 19, no. 1, pp. 36-42, Jan. 1975, doi: 10.1147/rd.191.0036.

[16] R. C Dorf, and J. A Svoboda, Circuit Theorems, in Introduction to Electric Circuits, 8th ed., Hoboken, NJ: John Wiley \& Sons. pp. 162-207, 2010.

[17] A. S. Adalev, M. Hayakawa, and N. V. Korovkin, "Identification of electric circuits: problems and methods of solution accuracy enhancement,” 2005 IEEE International Symposium on Circuits and Systems, 2005, pp. 980-983 Vol. 2, doi: 10.1109/ISCAS.2005.1464754. 
[18] A. S. Adalev, N. V. Korovkin, and M. Hayakawa, "Using Linear Relations Between Experimental Characteristics in Stiff Identification Problems of Linear Circuit Theory," in IEEE Transactions on Circuits and Systems I: Regular Papers, vol. 55, no. 5, pp. 1237-1247, June 2008, doi: 10.1109/TCSI.2008.924908.

[19] T. S. Shores, Applied Linear Algebra and Matrix Analysis, Berlin, Germany: Springer Science \& Business Media, 2007.

[20] C. B. Boyer, A History of Mathematics, 2nd ed., Hoboken, New Jersey: Wiley, 1968, pp. 431.

[21] L.G. Stokvis, (1914). On the creation of 3 harmonics in the alternators as a result of phase imbalance. Reports. vol.159: p.46. Comptes Rendus. vol.159: p.46.

[22] K. Miettinen, Nonlinear Multiobjective Optimization, Boston: Springer, 1999.

[23] N. Srinivas and K. Deb, "Muiltiobjective Optimization Using Nondominated Sorting in Genetic Algorithms," in Evolutionary Computation, vol. 2, no. 3, pp. 221-248, Sept. 1994, doi: 10.1162/evco.1994.2.3.221.

[24] K. Deb, A. Pratap, S. Agarwal and T. Meyarivan, "A fast and elitist multiobjective genetic algorithm: NSGA-II," in IEEE Transactions on Evolutionary Computation, vol. 6, no. 2, pp. 182-197, April 2002, doi: $10.1109 / 4235.996017$.

[25] Hongbing Fang, Qian Wang, Yi-Cheng Tu and Mark F Horstemeyer, "An efficient non-dominated sorting method for evolutionary algorithms," Evol Comput., vol. 16, no. 3, pp. 355-384, 2008, 10.1162/evco.2008.16.3.355.

[26] G. Nadakuditi, V. Sharma and R. Naresh, "Application of non-dominated sorting gravitational search algorithm with disruption operator for stochastic multiobjective short term hydrothermal scheduling", IET Generation, Transmission \& Distribution, vol. 10, no. 4, pp. 862-972, March 2016, doi: 10.1049/iet-gtd.2014.1137.

[27] S. Gerbex, R. Cherkaoui and A. J. Germond, "Optimal location of multi-type FACTS devices in a power system by means of genetic algorithms," IEEE Transactions on Power Systems, vol. 16, no. 3, pp. 537-544, Aug. 2001, doi: $10.1109 / 59.932292$.

[28] X.-P. Zhang, C. Rehtanz, and B. Pal, Flexible AC Transmission Systems: Modelling and Control, Berlin: SpringerVerlag Berlin Heidelberg, 2006.

[29] E. Acha, C. R. Fuerte-Esquivel, H. Ambriz-Perrez, and C. Angeles-Camacho, FACTS. Modelling and Simulation in Power Networks, England: John Wiley \& Sons Ltd, 2004.

[30] N. V. Korovkin, V. L. Chechurin, and M. Hayakawa, Inverse problems in electric circuits and electromagnetics, New York: Springer, 2006.

[31] S. Li, Y. Li, J. Sun, Q. Jin, and X. Li, "A novel control algorithm for inverter-based distributed generation in unbalanced three-phase power systems," 2009 International Conference on Sustainable Power Generation and Supply, 2009, pp. 1-6, doi: 10.1109/SUPERGEN.2009.5348276.

[32] B. Mahdad, T. Bouktir, and K. Srairi, "A Three-Phase Power Flow Modelization: A Tool for Optimal Location and Control of FACTS Devices in Unbalanced Power Systems," IECON 2006 - 32nd Annual Conference on IEEE Industrial Electronics, 2006, pp. 2238-2243, doi: 10.1109/IECON.2006.347766.

[33] T. C. Tran, P. Brandstetter, V. H. Duy, H. H. Vo, C. D. Tran and S. D. Ho, "Rotor Time Constant Estimation of Induction Motor Using Online PI-Adaptive and GA-Adaptive Model," in International Conference on Advanced Engineering Theory and Applications, 2017, pp. 860-871, doi: 10.1007/978-3-319-69814-4_83.

[34] C. D. Tran, P. Brandstetter, M. H. C. Nguyen, S. D. Ho, P. N. Pham, and B. H. Dinh, "An Improved CurrentSensorless Method for Induction Motor Drives Applying Hysteresis Current Controller," Indonesian Journal of Electrical Engineering and Informatics (IJEEI)., vol. 9, no. 1, pp. 130-140, 2021, doi: 10.52549/ijeei.v9i1.1619.

[35] S. D. Ho, P. Palacky, M. Kuchar, P. Brandstetter, and C. D. Tran, "Particle swarm optimization-based stator resistance observer for speed sensorless induction motor drive," International Journal of Electrical and Computer Engineering., vol.11, no. 1, pp. 815-826, 2021, doi: 10.11591/ijece.v11i1.pp815-826.

[36] S. D. Ho, P. Brandstetter, P. Palacky, M. Kuchar, B. H. Dinh, and C. D. Tran, "Current sensorless method based on field-oriented control in induction motor drive," Journal of Electrical Systems., vol. 17, no. 1, pp. 62-76, 2021.

[37] H. H. Vo, T. C. Tran, S. Dang Ho, C. Dinh Tran, P. Brandstetter, and M. Kuchar, "Fuzzy model-based speed observer for sensorless induction motor drive with PWM-DTC," 2018 ELEKTRO, 2018, pp. 1-5, doi: 10.1109/ELEKTRO.2018.8398306. 